\title{
Shear settling in laminar open channel flow: analytical solution, measurements and numerical simulation
}

\author{
AM Talmon Deltares and Delft University of Technology, The Netherlands \\ L Sittoni Deltares, The Netherlands \\ E Meshkati Shahmirzadi Deltares, The Netherlands \\ JU Hanssen Deltares, The Netherlands
}

\begin{abstract}
In beaching of tailings, sand and clays may segregate. In laminar flow this is due to shear settling. First implementations of shear settling in numerical flow models are seen, offering unprecedented potential to conduct tailings management studies. In order to validate numerical codes, reference materials are necessary. For laminar flow, there is a small set of flume tests available from an earlier study. An analytical solution for transient sand concentration profile development with distance in laminar open channel flow appeared recently. This analytical method is more complete than an analytical model developed earlier at the author's institute. Data and analytical solutions are analysed and applied to serve for the validation of numerical flow simulation of beaching in tailings storage facilities. Fair agreement is observed between measurements and the analytical method. Moreover, fair agreement is obtained between an earlier produced computational outcome of the numerical model Delft3D-slurry and analytical solution. This contributes to building confidence in this model as an aid in supporting tailings deposition management.
\end{abstract}

Keywords: one-way coupling, beaching, rheology, shear settling, segregation, tailings management

\section{Introduction}

In beaching, many deposits show channel formation. Initially, semi-radially extending deposits may develop, but after a while the flow chooses a preferential direction. This may lead to elongated lobes or channels. Sand settling is believed to be the basis for channel formation and migration. Channels are one of the most important features of beach deposits. Sand settling and segregation is therefore at the core of beach development. Understanding channelisation is important to assess and predict tailings beach geometry, slope, composition (i.e. areas of fines and sand), fines capture, fines production, but also long-term consolidation performance, and therefore closure planning. Improving prediction of tailings deposition can therefore save significant cost and reduce liability to the tailings industry, as it moves into thicker flocculated tailings, with pressure to limit legacy and current fluid fine tailings volumes and minimise future closure plan liability. In this paper the authors present a practical data-theory-numerical approach to aid tailings management.

Deposition principles are often tested in laboratories by running (model) tailings through flumes and by pouring (model) tailings. Deposits display gelled character (absence of sand skeleton), and may not necessarily come to a final halt. We have, for instance, witnessed that in a $25 \mathrm{~m}$ long flume, tailings flow can come to a temporally halt, to be remobilised again later (Sisson et al. 2012). Nevertheless our knowledge on the development of flow and deposition needs to extend to a larger scale. Time scales and distances in prototype are much larger than in laboratory testing. The in-house laboratory test described in van Kesteren et al. (2015), (50 m length, $5.5 \mathrm{~m}$ wide) is the closest one gets to prototype dimensions. It is important to understand deposition pattern formation: it determines the flow regime and deposition regime. Pattern formation is likely to be governed by time-dependent rheological properties, structure changes in the clay, sand settling and dewatering (Figure 1). Sand settling is a process that leads to a liberation of clays from the slurry, contributing to the production of fluid fine tailings. Therefore, this process is taken on first. 


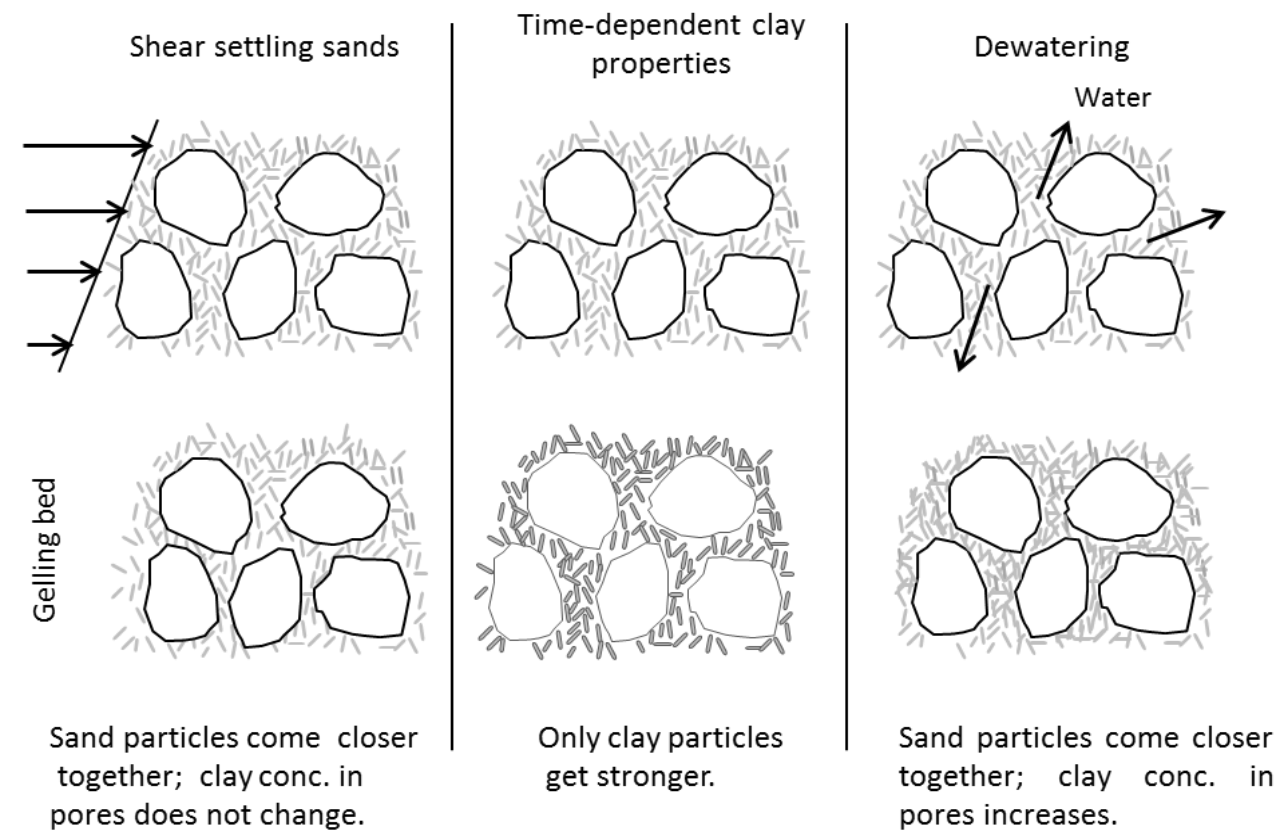

Figure 1 Changing properties of sand-carrier mixtures by different physical processes

Laboratory tests under controlled conditions (Sanders et al. 2002; Spelay 2007) have shown the commencement, i.e. first signs of segregation within the flow. With strong rheological properties, the tailings can only flow in the laminar regime. Conveyed solids, however, deposit slowly due to shear within the flow.

Settling of particles in shear, whereas they do not settle at rest, is a known phenomenon, quantified for single particles by Thomas (1979), Wilson and Horsley (2004), Talmon and Mastbergen (2004) and Pullum et al. (2010), and for multiple particles settling simultaneously (Cooke 2002; Pirouz et al. 2008; Talmon et al. 2014a; Ovarlez et al. 2012). Solids settling in shear flow is called shear settling or dynamic settling. Shear settling in laminar flow starts being implemented in multi-dimensional computational fluid dynamics (CFD) simulations (Sittoni et al. 2016; Treinen 2017; van Rhee 2017). A sketch of the internal physical processes in laminar open channel flow is given in Figure 2. At elevated yield stresses, such as of thickened tailings, a gelled bed is formed (Talmon et al. 2014b).

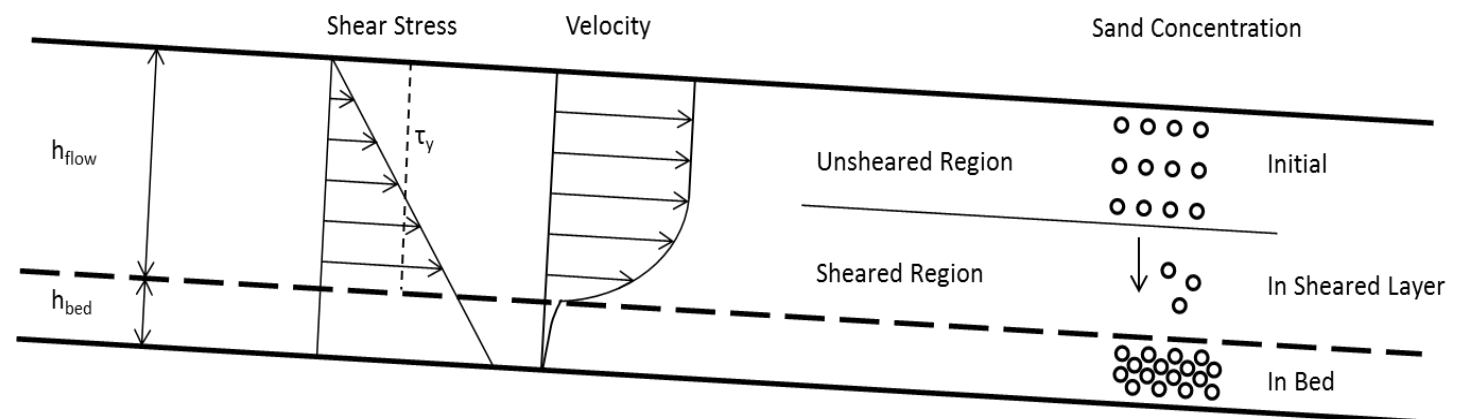

Figure 2 Sketch of internals of laminar open channel flow (yield stress fluid)

It is rather involved to analyse/simulate three dimensional flow, so simplifications into one and two-dimensional systems have been pursued still capturing essentials (Sittoni et al. 2016; Treinen 2017); refer to Figure 3 for definitions. For 3D we intend simulation of the entire deposit for a portion of time with variability in $\mathrm{x}-, \mathrm{y}$ - and depth, including channel formation. With 2D we intent a longitudinal cross-section with variability in $x$-and depth. $1 D V$ is a single profile with variability in depth only. 
An example of a numerical calculation of tailings deposition and sand segregation along a longitudinal beach cross-section is shown in Figure 4. Analytical linear theories for segregation in these open channels are provided by Sisson et al. (2012) (1DV), Childs (2013) (2DV) and Childs et al. (2016). Gelled bed formation is not contained in these analytical approaches. These analytical theories may serve to validate numerical models and extrapolate beyond limited length of test flumes.

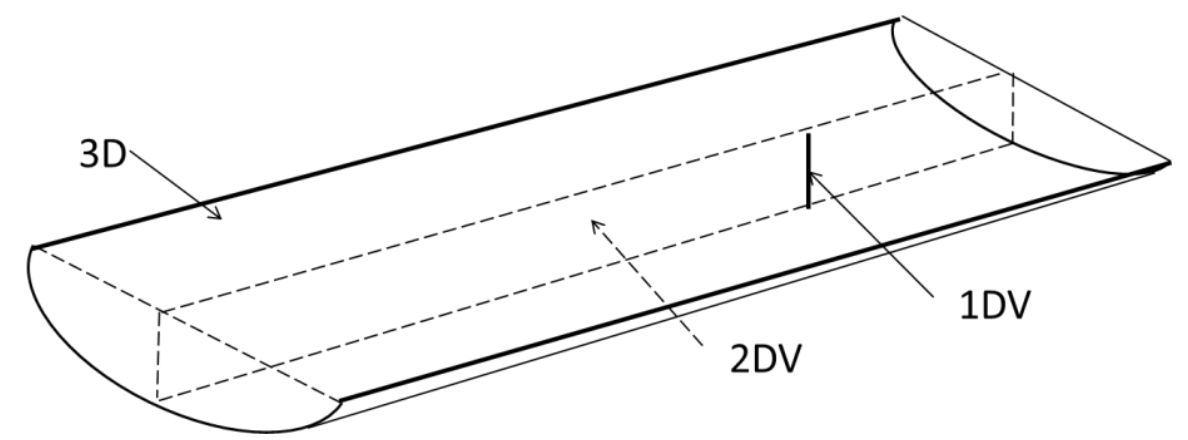

Figure 3 Definition of the 3D, 2DV and 1DV theoretical/numerical domain in open channel flow

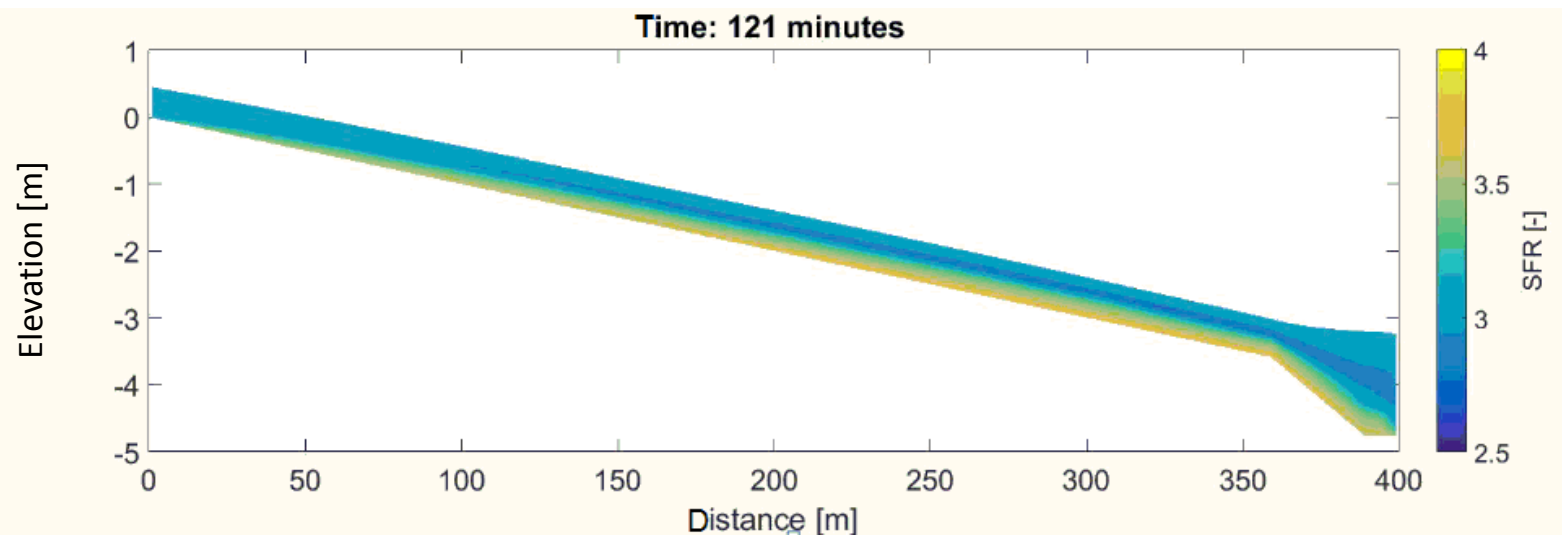

Figure 4 Oil sand tailings beaching calculated with Delft3D in 2DV configuration ( $i=0.01, d=0.1 \mathrm{~mm}$, $q=0.1 \mathrm{~m}^{2} / \mathrm{s}$, Bingham model $\tau_{y}=40 \mathrm{~Pa}$, sand fines ratio at tailings discharge pipe: $S F R=3$ )

One-dimensional 1DV configuration CFD studies were conducted by Spelay (2007), Hanssen (2016) and van Es (2017). CFD models for the 2DV configuration with free surface were developed and reported by Treinen (2017) and van Es (2017). A full 3D simulation with rigid lid is conducted by van Rhee (2017). Treinen and van Rhee compared CFD results with Spelay's measurements.

The model of Treinen is built from scratch. The model of van Rhee is created from building blocks provided by OpenFOAM. The simulations described by Sittoni et al. (2016) are performed with a special research version of Delft3D (Deltares 2017), which is already capable of delta formation calculations, and is being updated to include non-Newtonian tailings types of slurries. In upgrading codes, systematic validations are necessary. Analytical solutions for simplified conditions are equally as important as test data. However, analytical solutions can also be applied for a quick assessment of segregation conditions.

The Sisson analytical model describes longitudinal uniform time-dependent development of solids concentration and segregation in wide open channel flow. The analytical approach developed by Childs describes transient concentration profile development and segregation with distance.

For upgrading the Delft3D code with non-Newtonian flow simulation capabilities (i.e. Delft3D-slurry), a systematic validation of the new implementations is necessary. Validation can be performed through comparing the numerical results with datasets as well as with the output of analytical solutions. This enables us to verify the capability of the code on prototype time and length scale. 
Agreement between data, theory and analytical/numerical simulation is central to build trust in a model that is utilised to support tailings management decisions. Therefore an analysis is conducted between correspondence of measurements of Spelay on model thickened tailings (TT) in a 3D conduit, the analytical solutions of Childs and Sisson and an existing calculation of the Delft3D numerical code.

This paper presents a robust data-theory-analytical/modelling approach to verify the capability of Delft3D-slurry in prediction of sand settling in thick tailings (i.e. laminar non-Newtonian) deposition. As the industry moves into thicker centrifuge and flocculated tailings, with pressure to limit legacy and current fluid fine tailings volumes, it is the opinion of the authors that Delft3D-slurry is a critical tool to optimise current operations and minimise future closure plan liability, and with potentially significant cost reduction for each oil sands operator.

\section{Analytical theory}

\subsection{Analytical segregation model}

Shear settling at high concentration is a non-linear problem. Non-linear processes are hindered settling, dual rheology (also known as rheology augmentation and inherent viscosity, Thomas 2010) and two-way coupling (the velocity profile influences the concentration profile and vice versa). The existing analytical theories apply to laminar flow of Oswald-de Waele power law fluids: $\tau=K(\dot{\gamma})^{n}$ where $K=$ consistency index, $n=$ flow index and $\dot{\gamma}=$ shear rate. A low $n$ exponent may suffice to simulate yield stress $\left(\tau_{\mathrm{y}}\right)$ presence, mimicking plug-like velocity profiles (Figure 5). Further assumptions in these theories are mono-sized settling solids, constant rheological properties (no variation in time and/or space), homogenous carrier (clay dominated fraction), shear settling of coarse particles (governed by local apparent viscosity: Stokes regime) and energy slope equals channel slope (constant flow depth).

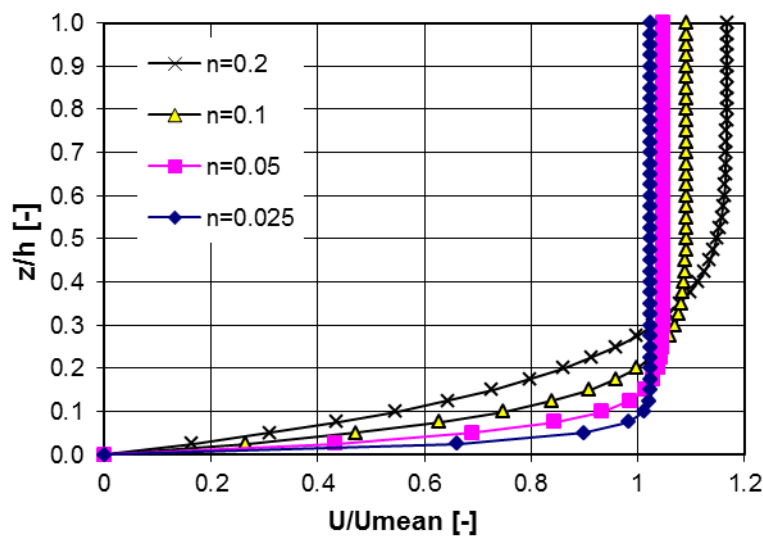

(a)

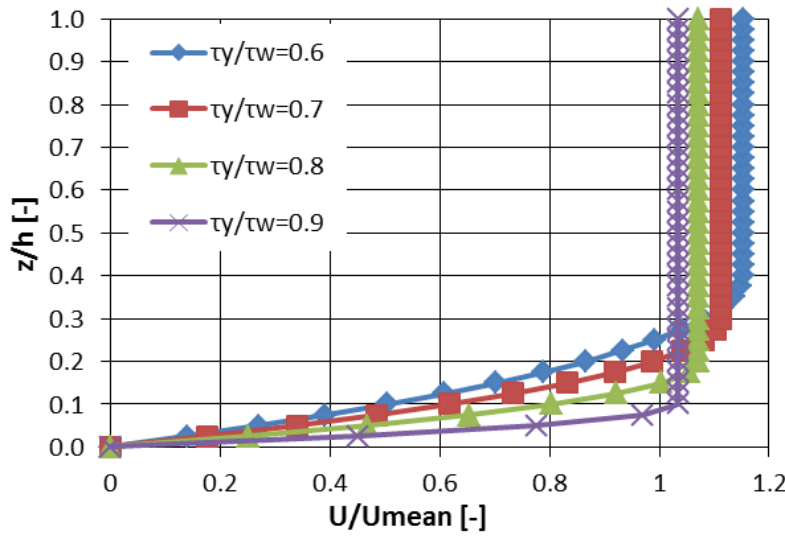

(b)

Figure 5 (a) Power-law velocity profile for different values of the flow index $n$; (b) Bingham velocity profiles for different ratio of yield stress $\tau_{\mathrm{y}}$ and wall shear stress $\tau_{\mathrm{w}}$

An analytical approach is only possible when the mathematical system is simplified into a linear system: no yield stress, power law model, no hindered settling, single rheology, one-way coupling (no influence of the variation of sand concentration on the flow field). In this linear system, the mathematical method of characteristics is applied to solve the continuity equation of settling solids. The Sisson analytical model assumes lengthwise uniform conditions and calculates time-dependent development of a 1DV concentration profile. The Childs analytical model describes lengthwise transient, time-independent, 2DV concentration profile development. 
We focus here on the analytical theory of Childs since it gives an exact solution in two dimensions, instead of the one-dimension theory by Sisson. With particle settling in the Stokes regime, the dimensionless horizontal coordinate of Childs et al. (2016) is cast into:

$$
x^{\wedge}=\frac{x}{h} \frac{W}{U_{\text {childs }}}=\frac{x}{h} \frac{1}{i} \frac{1}{18} \frac{\Delta \rho}{\rho} \frac{d^{2}}{h^{2}}
$$

where:

$$
\begin{aligned}
& W \quad=\text { settling velocity solids at bed level. } \\
& x \quad=\text { longitudinal coordinate. } \\
& h \quad=\text { flow depth. } \\
& i \quad=\text { slope. } \\
& d \quad=\text { particle diameter. } \\
& U_{\text {childs }}=\text { characteristic flow velocity. } \\
& \Delta \rho \quad=\text { submerged density coarse solids. } \\
& \rho \quad=\text { density carrier fluid. } \\
& x^{\wedge} \quad=\text { dimensionless horizontal coordinate. }
\end{aligned}
$$

Notice that in this definition $x^{\wedge}$ is independent of rheological parameters $(K, n)$, but is related to the depth averaged horizontal flow velocity by:

$$
U_{\text {childs }}=\frac{2 n+1}{n} \bar{U}
$$

where:

$$
\bar{U} \quad=\text { depth averaged flow velocity. }
$$

The rheological parameters $(K, n)$ are indirectly accounted for: the flow depth is, at the given specific flow rate, density and beach slope, governed by the rheological properties of the mixture. In Sisson et al. (2012) the vertical concentration profile evolves in time, as a dimensionless parameter for time:

$$
t^{+}=\frac{W}{h} t
$$

where:

$$
\begin{aligned}
t & =\text { time. } \\
t^{+} & =\text {dimensionless time. }
\end{aligned}
$$

At $t^{+}=1$, a particle having a constant settling velocity has settled over the entire depth.

For $n=1$ the settling velocity is the same in the whole domain (Newtonian fluid: viscosity is independent of shear rate), and in this case $x^{\wedge}=1 / 3$ corresponds with the settling distance of a particle released at the water surface at the inlet of the channel. In case of a time-distance transformation, this corresponds to the Childs $x^{\wedge}$ coordinate as:

$$
x^{\wedge}=t^{+} \frac{n}{2 n+1}
$$


The original Childs model contains a superposition of static and dynamic shear settling. The static settling has been removed in our analysis. With reference to Chapter 5 of the PhD thesis by Childs (2013), the solution for the concentration distribution in the $2 \mathrm{DV} x-z$ plane is obtained by the mathematical method of characteristics, giving:

$$
x^{\wedge}=\frac{n}{n+1}\left[\frac{n}{2 n-1}(1-z)^{\frac{2 n-1}{n}}\left(1-C^{\frac{2 n-1}{1-n}}\right)-\frac{1}{3}(1-z)^{3}\left(1-C^{\frac{3 n}{1-n}}\right)\right]
$$

where:

$$
\begin{aligned}
& c \quad=c / c_{0} . \\
& c \quad=\text { volumetric solids concentration. } \\
& c_{0}=\text { uniform volumetric concentration of solids at } x=0 . \\
& z \quad=\text { dimensionless vertical coordinate mud layer }(z=0 \text { is bed level). }
\end{aligned}
$$

Figure 6 shows iso-concentration contours according to Childs and according to a downstream advected Sisson solution, where $c_{0}=$ uniform inlet concentration. Such graphs can be produced for different values of the flow index $n$. The graph shows for instance that at a dimensionless distance of $x^{\wedge}=0.1$ the concentration above the bed has dropped to $20 \%$ of the uniform concentration at inflow.

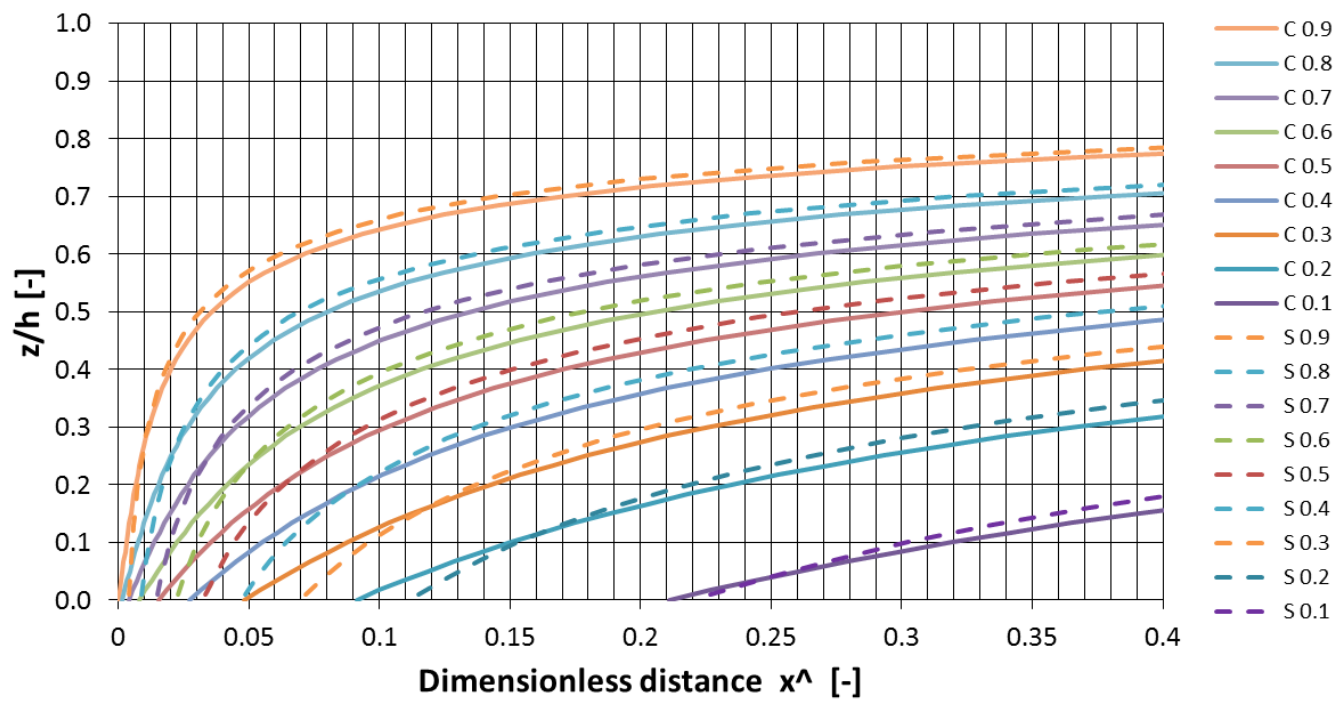

Figure 6 Iso-concentration contours $\left(c / c_{0}\right)$ for Childs $(C)$ and advected Sisson solution $(S), n=0.2$. Concentration contours are relative to uniform inlet concentration $\left(c_{0}\right)$

Figure 6 shows the gross correspondence between the theories. There are, however, differences in the lower $20 \%$ of the flow. This is caused by an absence of longitudinal transport gradients in the 1DV model described in Sisson et al. (2012).

Figure 7 shows how the concentration just above the bed decays with distance. A significant sensitivity to flow index $n$ is noticed. So in our application, mimicking yield stress fluids, care is to be exercised in determination of $n$. 


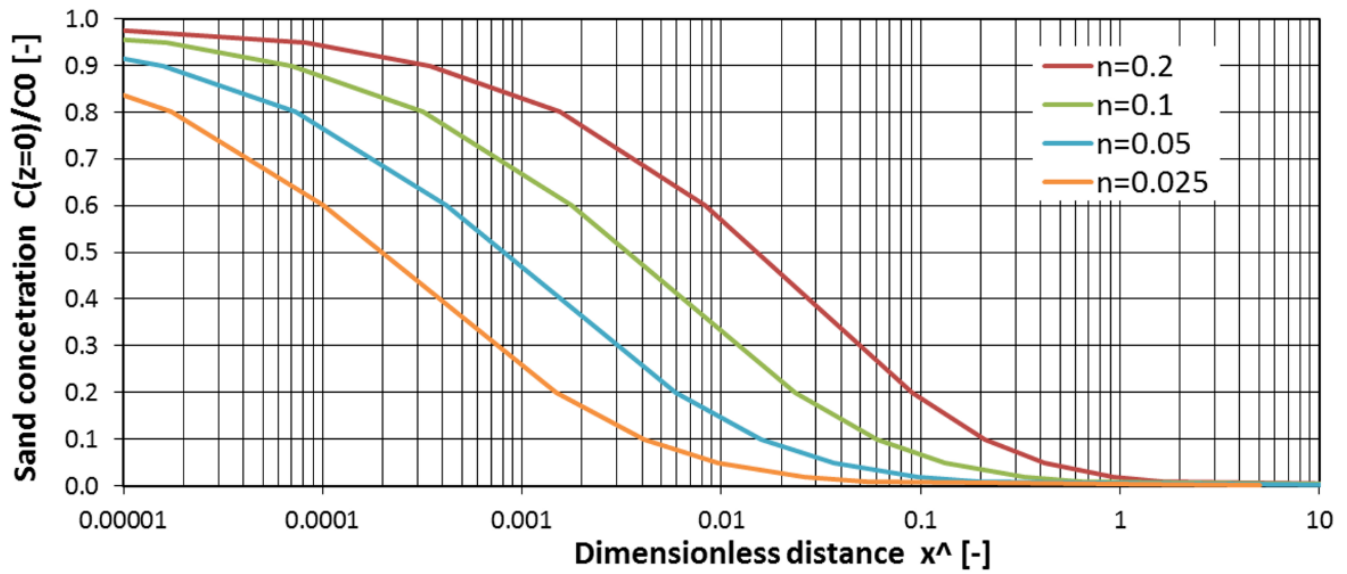

Figure 7 Sand concentration above the bed according to Childs' theory

The analytical theories are basically developed for low concentration linear systems. Non-linear hindered settling and rheology augmentation are beyond scope. It appears though that the influences of these two processes approximately cancel each other, as shown in Figure 8.

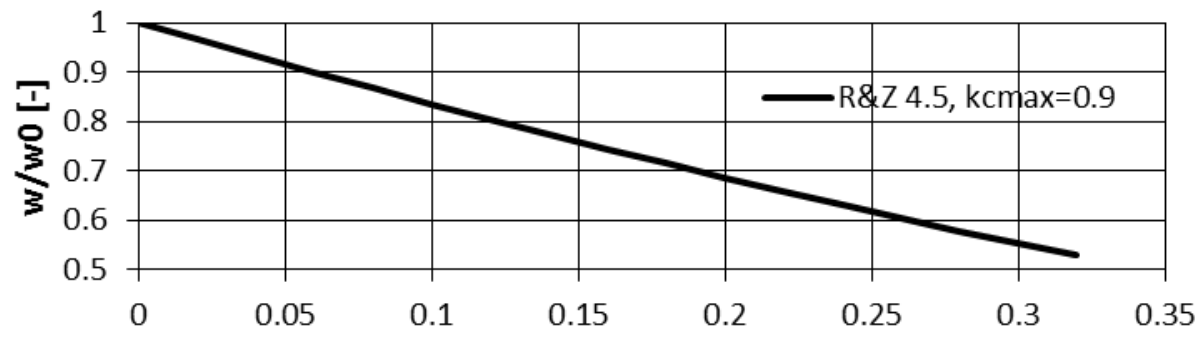

Concentration settling solids c [-]

Figure 8 Ratio of settling velocity (w) according to hindered settling in carrier fluid and the settling velocity of a single particle $\left(w_{0}\right)$ in a fictitious fluid with the same rheological properties as the solids suspension

Conditions for Figure 8 are Thomas (1999) rheology augmentation with $\mathrm{kc}_{\max }=0.9$, and hindered settling by Richardson and Zaki with exponent 4.5 (Stokes regime). Hindered settling, at for instance $10 \mathrm{v} \%$ sand, appears to be a bit stronger than the solids effect on rheology. As a net result, at $10 \mathrm{v} \%$ sand, the net settling velocity drops to about $84 \%$ compared to a single particle being assumed to settle in mixture rheology (which is the rheological reference in our linear analytical models), justifying application to higher concentrations. Other choices for the formulation of rheology augmentation and hindered settling are of course also possible (Figure 8 shows principle).

\subsection{Transformation theory 3D to 2DV}

In order to transform between 3D channel flow and a lower dimension, the hydraulic radius approach was followed by Spelay (2007) and was likewise adopted by Treinen (2017), keeping $R_{h}$ the same in 3D and 2DV. $R_{h}$ is the hydraulic radius and is defined as the cross-sectional area of the flow $(A)$ divided by the wetted perimeter of the channel $(P)$. The hydraulic radius approach ensures that the wall shear stress is the same for the same (energy) slope, mixture density and gravity:

$$
i \rho g A=P \tau_{w}, i \rho g R_{h}=\tau_{w}
$$

Indeed the wall shear stress should be kept the same in transformation because this provides similarity in laminar now-Newtonian flow profiles of different geometrical dimension (unchanged rheological parameters). Kinematic similarity (congruent particle trajectories) is also important. There are various options to achieve this. 
Table 1 shows alternative approaches to ensure similarity, if Spelay's test conditions are simplified to a pipe flowing half-full, similar for other channel geometries. Notice that for a pipe per definition $R_{\mathrm{h}}=D / 4$ (flowing full and flowing half-full), $D=$ pipe diameter. The transformation scale of velocity $U$ follows from consideration of bulk shear rate which should remain the same for identical wall shear stress. The bulk shear in a pipe is $2 U / R_{\mathrm{h}}$, and the bulk shear rate in a wide open channel is $3 U / R_{\mathrm{h}}$. The velocity profiles are the same but average flow velocities are different due to different integration domain.

Table 1 Different scenarios to transfer from 3D to 2DV for half-full circular cross-section

\begin{tabular}{|c|c|c|c|}
\hline $\begin{array}{l}\text { Parameter } \\
\text { (pipe:wide channel) }\end{array}$ & A scenario & B scenario & $\begin{array}{l}\text { C scenario } \\
\text { (Spelay and Treinen) }\end{array}$ \\
\hline Depth $h(\mathrm{~m})$ & $1: 1$ & 1:0.5 & $1: 0.5$ \\
\hline Length $x(m)$ & $1: 1$ & 1:0.5 & $1: 0.25$ \\
\hline Particle diameter $d(\mathrm{~m})$ & $1: 1$ & 1:0.707 (Stokes) & $1: 1$ \\
\hline Concentration sand & $1: 1$ & $1: 1$ & $1: 1$ \\
\hline Settling velocity $W(\mathrm{~m} / \mathrm{s})$ & $1: 1$ & 1:0.5 & $1: 1$ \\
\hline Flow velocity $U(\mathrm{~m} / \mathrm{s})$ & $1: 2 / 3$ & $1: 1 / 3$ & $1: 1 / 3$ \\
\hline$\tau_{\mathrm{w}}(\mathrm{Pa})$ & $1: 1$ & $1: 1$ & $1: 1$ \\
\hline$i(-)$ & $1: 0.5\left(1 / R_{\mathrm{h}}\right)$ & $1: 1$ & $1: 1$ \\
\hline$R_{h}(-)$ & $1: 2$ & $1: 1$ & $1: 1$ \\
\hline Assumptions & $\begin{array}{l}x-y \text { geometric and } \\
\text { kinematic similarity }\end{array}$ & $\begin{array}{l}\text { Hydraulic radius and } \\
\text { kinematic similarity }\end{array}$ & Hydraulic radius only \\
\hline
\end{tabular}

In Spelay and Treinen the hydraulic radius $R_{h}$, the wall shear stress and channel slope are taken the same in transformation from 3D to lower dimension. Thus the vertical length scale is about halved: scenario B or C. The flow velocity is consequently a factor of two lower (identical bulk shear rate for equal wall shear stress $\tau_{\mathrm{w}}$ ), but the settling velocity is kept equal (same wall shear stress, and therefore same apparent viscosity at the wall, and with the same particle diameter, the settling velocity is the same). Thus, first, for halved flow depth the particle will settle in half the distance and second for half horizontal flow velocity the particle will settle another half distance shorter. Therefore Spelay and Treinen's calculation results should be evaluated at about $3.5 \mathrm{~m}$ instead of at a distance of $14 \mathrm{~m}$ where the instrumentation was situated in the experiment.

\section{$3 \quad$ Measurements}

Measurements on settling solids in open channel flow were conducted by Sanders et al. (2002) and Spelay (2007). Their test section consists of an open cut pipe and the suspension flowed at a depth of about $D / 2$. Associated rheology had to be revisited to relate to the analytical theories which are based on power law rheological characterisation.

\subsection{Typical open channel test results laminar flow}

Measurements took place near the end of a circa $18 \mathrm{~m}$ long open channel test pipe of $0.156 \mathrm{~m}$ diameter. Figure 9 shows measured concentration profiles in mid-plane for laminar flow of model thickened tailings (Spelay 2007). The figure shows a decay of 2 to $3 \%$ in total solids concentration at about $1 / 4$ of total depth. The tailings consist of clays and sands. The sand concentration in these tests was $14 \%$, median diameter $0.19 \mathrm{~mm}$. Gelled bed formation as can be seen in the lower $1 / 4$ of the profile is not described by the analytical theories. The increased concentration at the bottom of the pipe corresponds qualitatively with 
the numerical calculation in Figure 4. Also, the local decrease in concentration above the bed corresponds qualitatively with the numerical calculation.

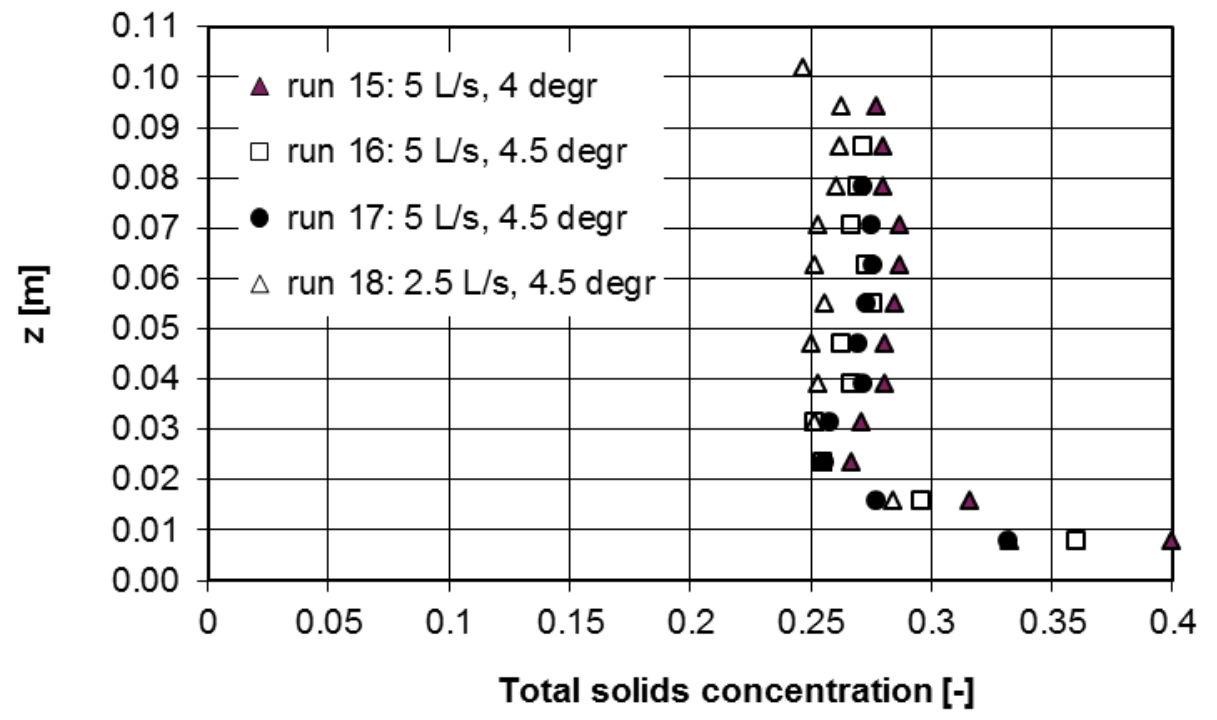

Figure 9 Measured total concentration profiles of model TT (Spelay 2007)

\subsection{Rheology}

Spelay characterised the $T \mathrm{~T}$ mixtures as Bingham fluids. The rheology, though, has to be expressed as a power law to be used in the analytical theories. Pressure loss measurements at the feed pipe to the flume (test pipe with top sections cut out for instruments), conducted for a variation of flow rates, were originally used for rheological characterisation (pipe viscometer principle). These were not conducted at the same instant as the open channel tests. These feed pipe rheology measurements, conducted at the beginning and end of Spelay's test days, show distinct differences. In addition to his PhD thesis data, Spelay provided additional feed pipe pressure loss data monitored during the actual flume measurement, to better quantify associated rheology.

Spelay originally fitted the Buckingham equation (Bingham model) through the data points of the feed pipe. Here we characterise the rheology by power law, utilising the Rabinowich-Mooney transformation for laminar pipe flow (Figure 10). The Rabinowich-Mooney transformation is only applied at the time instant of open channel measurements. The results are listed in Table 2.

Table 2 Power law rheology for TT experiments (run 15-18), per monitored pressure drop over the feed pipe during the experiments

\begin{tabular}{llll}
\hline Experiment & $\mathbf{K}^{\prime}$ & $\mathbf{K}$ & $\mathbf{n}$ \\
\hline Run 15 & 32.87 & 29.00 & 0.121 \\
Run 16 & 32.69 & 28.76 & 0.132 \\
Run 17 & 36.43 & 32.07 & 0.131 \\
Run 18 & 42.73 & 37.93 & 0.103 \\
\hline
\end{tabular}



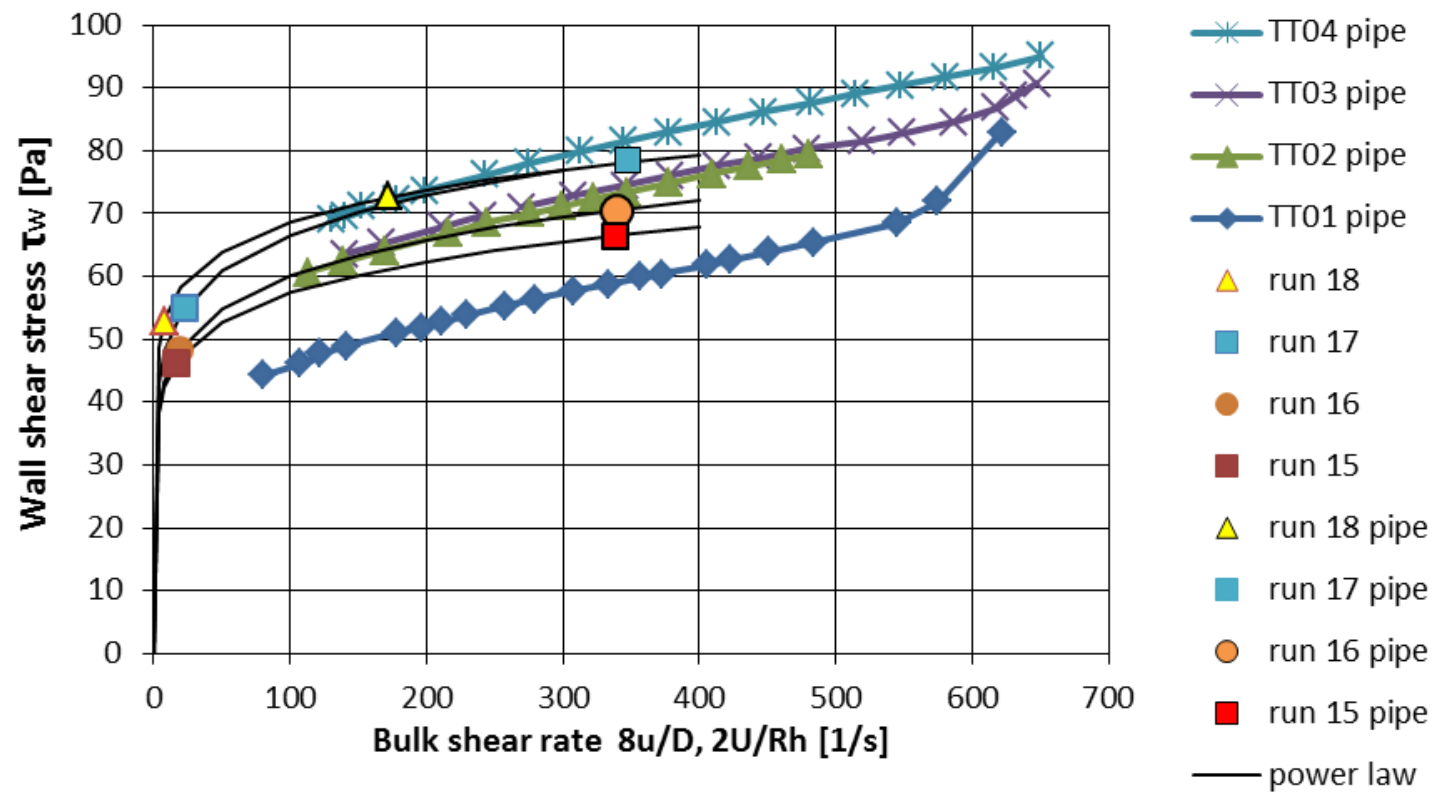

Figure 10 Measurements and power law approach for rheology. 'TT0x' is pipe viscometry at beginning and end of test day, 'run $\mathrm{xx}^{\prime}$ is during test

\section{Comparison}

Decay of sand concentration in measurement, numerical and analytical are compared. Comparisons are conducted on equal grounds (Section 2.2). Measurement and numerical are observed to correspond qualitatively (Section 3.1). Here a quantitative comparison is pursued between the different approaches. A strict comparison between analytical and numerical, ideally conducted to test for numerical accuracy, is not yet possible because of different boundary conditions (open versus closed bottom boundary).

\subsection{Analytical calculations versus measurement}

The two different analytical solutions are mutually compared and a comparison with the measurements is undertaken based on preparatory rheological characterisation of the open channel tests and transformation between 2D and 3D (scenario A).

Figure 11 shows the analytical solutions projected on test data with channel slope $4.5^{\circ}$. The analytical solutions base on a flow depth of $0.09 \mathrm{~m}$, sand diameter of $0.19 \mathrm{~mm}, n=0.12$, a reduction of settling velocity of $23 \%$ per Figure $8, \Delta \rho=1,420 \mathrm{~kg} / \mathrm{m}^{3}$ and $\rho=1,230 \mathrm{~kg} / \mathrm{m}^{3}$.

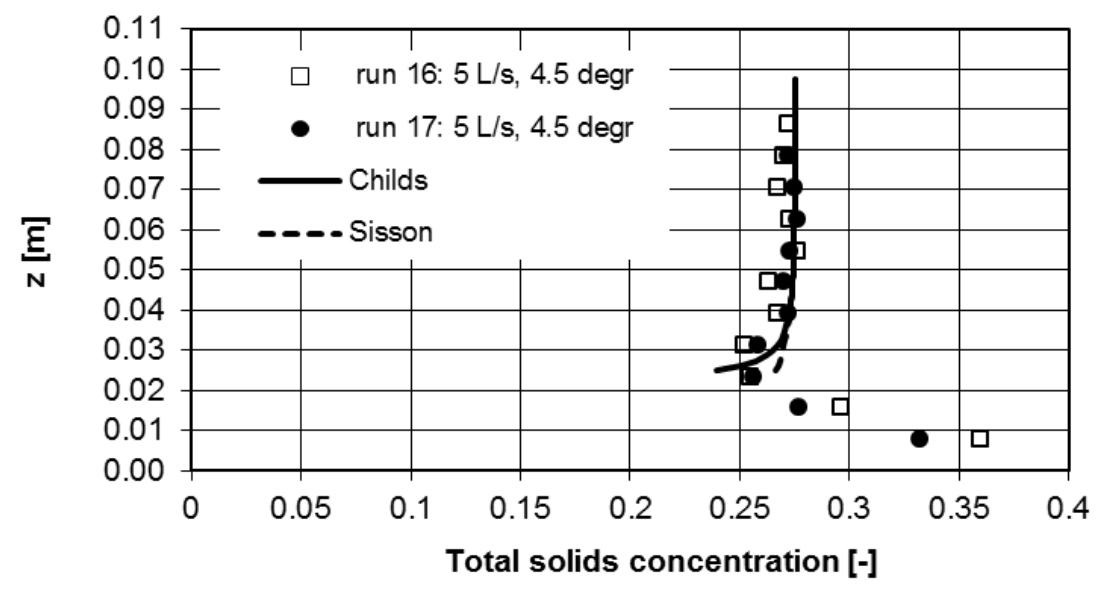

Figure 11 Measured and calculated concentration profile for model TT tests at a dimensionless distance $x^{\wedge}=0.00085$ 
Comparison with the data shows that the theories describe the decay of concentration fairly well. It is to be noted that the smooth transition to the gelled bed layer is not described by either of these models. The calculated back-drop at the lowest vertical location is therefore a bit too strong. Comparison of the two solutions in Figure 11 reveals again that advection of the Sisson 1DV solution by the flow works fine for the high velocity part in the upper part of the profile, but leads to differences with the full 2DV solution in the lower portion of the concentration profile where the flow velocities are lower.

\subsection{Numerical calculation versus analytical}

For the numerical simulation shown in Figure 4, the dimensionless distance at $300 \mathrm{~m}$ onto the beach is $x^{\wedge}=0.00043(-)$. In the calculation, the depth of the flowing mud layer varies from $0.4 \mathrm{~m}$ upstream to $0.2 \mathrm{~m}$ at $300 \mathrm{~m}$. Average depth is thus $0.3 \mathrm{~m}$. Sand diameter is $0.1 \mathrm{~mm}$ and beach slope is $1 \%$. Volumetric sand concentration is $30 \%$. The yield stress is $40 \mathrm{~Pa}$ and the bottom shear stress about $60 \mathrm{~Pa}$. Therefore an $n$ value of 0.2 is the more appropriate (Figure 5). This gives $10 \%$ decay of sand concentration according to Figure 7, corresponding to the lowest concentration indicated in Figure 4 (dark blue). The theoretical analytical sand concentration profiles are projected onto the numerical calculation results of Delft3D in Figure 12, showing fair agreement between the analytical solution of Childs and the numerical calculation.

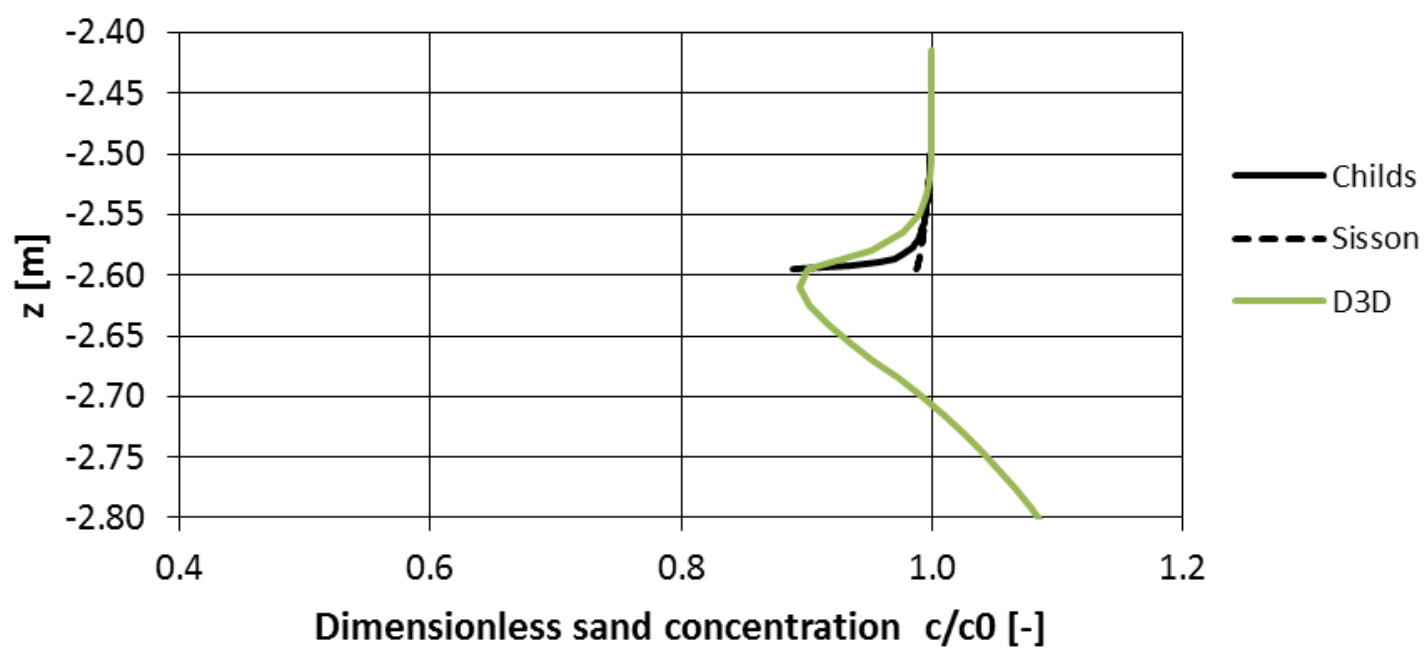

Figure 12 Calculated analytical concentration profiles and Delft3D numerical calculation of Figure 4 at $300 \mathrm{~m}$

\section{$5 \quad$ Evaluation}

In addition to the conducted analysis, the linear analytical theory is also a tool to understand primary dependencies, and can be applied as a reference for verification of numerical computations (CFD) under simplified and well defined circumstances. Childs' solution is available to test for numerical diffusivities and grid resolution, provided that the lower boundary is opened for settling solids.

The linear model reveals the most important interdependencies per Equation 1, which basically quantifies settling distance per particle trajectory (kinematic similarity). This basic equation shows that the ratio of particle diameter and flow depth is the governing parameter. For example, for $0.2 \mathrm{~mm}$ sand, as more common in oil sands and weaker slurries flowing at $0.1 \mathrm{~m}$ depth for instance, this would drastically change into $x^{\wedge}=0.046(-)$. According to the Childs model (Figure 7) this would give a $70 \%$ decay of concentration above the bed at $300 \mathrm{~m}$. This implies that the assumed one-way coupling in Childs' theory does not hold anymore, and a non-linear model is to be applied. This comparison indicates that the analytical solution can also be used for a quick assessment of segregation conditions.

The procedure to apply the analytical approach for quick assessment of segregation conditions is: first, calculate flow depth using standard methodology for Bingham homogenous fluids and calculate plug size. The ratio flow depth/plug size equals $\tau_{\mathrm{y}} / \tau_{\mathrm{w}}$. Then, apply Figure 5 to determine the appropriate flow index $n$. 
Finally, apply Figure 7 to determine relative sand concentration above the bed, after calculation of the dimensionless distance by Equation 1. In application of the analytical theory, the results are sensitive to the $n$ value, which is therefore to be determined with care. Application of a regression analysis procedure to fit flow profiles could be beneficial.

Another observation is that if 2DV conditions are compared to 3D conditions on the basis of equal hydraulic radius and equal wall shear stress, kinematic similarity is not satisfied. It is better to simulate on the basis of equal flow depth and equal wall shear stress, hence smaller energy slope. By using relatively coarser sand, the physical settling distance can be made artificially shorter in laboratory testing.

Measurement, analytical theory and numerical simulation serve the common objective. The presented analytical theories necessarily assume one-way coupling. Two-way coupling is necessary for conditions of significant decrease in concentration, quantifiable with numerical modelling. We have now seen cases with mild segregation, still described by linear theory. The problem is fundamentally non-linear and numerical modelling is needed. The analytical method may help to indicate whether detailed internal resolution is necessary or computational efforts are better spent in capturing other aspects of deposition.

Gelled bed formation is not described by the analytical models. Gelled bed development follows rheological principles (Talmon et al. 2014b). It would be interesting to see whether under the encountered mild segregation conditions gelled bed development can also be analytically quantified.

\section{Conclusion}

Measurements, analytical theory and numerical simulation show a decrease in concentration of similar magnitude in the lower part of the flow. The analytical solution shows that the ratio particle diameter/flow depth is an important parameter to the development of sand segregation within the flow. Another insight is that if 2DV conditions are compared to 3D conditions on the basis of equal hydraulic radius, kinematic similarity is not satisfied. It is better to simulate on the basis of equal flow depth.

Upon comparison, the more complete Childs solution shows a greater decrease of concentration at the bottom than the Sisson model. Both analytical solutions cannot predict the formation of a gelled bed, since settled solids disappear through the bottom boundary of the analytical model and because the physics leading to a gelled bed are not included (rheology augmentation and two-way coupling). The Childs solution can however be utilised for quick assessment of segregation conditions.

Fair agreement is observed between measurements and Childs' analytical method. Moreover, fair agreement is also observed between an earlier produced computational outcome of the numerical model Delft3D-slurry and analytical solution. This serves in building confidence in this numerical model as an aid to support tailings deposition management studies.

\section{Acknowledgement}

Sisson's analytical solution for concentration profile was devised by WGM van Kesteren. Thanks to Dr RB Spelay for providing additional data. The authors acknowledge the Institute for Oil Sand Innovation (IOSI) and Canada's Oil Sands Innovation Alliance (COSIA) for providing the funds for this research.

\section{References}

Childs, LH 2013, Low Reynolds Number Flows of Generalized Non-Newtonian Fluids, PhD thesis, University of Bristol, Bristol.

Childs, LH, Hogg, AJ \& Pritchard, D 2016, 'Dynamic settling of particles in shear flow of shear thinning fluids', Journal of Non-Newtonian Fluid Mechanics, vol. 235, pp. 83-94.

Cooke R 2002, 'Laminar flow settling: the potential for unexpected problems', Proceedings of the 15th International Conference on Hydraulic Transport of Solids in Pipes: Hydrotransport 15, BHR Group, Cranfield, pp. 121-133.

Deltares 2017, Delft3D, computer software, Deltares, Delft, http://oss.deltares.nl/web/delft3d

Hanssen, JLJ 2016, Towards Improving Predictions of Non-Newtonian Settling Slurries With Delft3D: Theoretical Development and Validation in $1 D V$, MSc thesis, Delft University of Technology, Delft. 
Ovarlez, G, Bertrand, F, Coussot, P \& Chateau, X 2012, 'Shear-induced sedimentation in yield stress fluids', Journal of Non-Newtonian Fluid Mechanics, vol. 177-178, pp. 19-28, https://doi.org/10.1016/j.jnnfm.2012.03.013

Pirouz, B, Kavianpour, MR \& Williams, P 2008, 'Sheared and un-sheared segregation and settling behavior of fine sand particles in hyperconcentrated homogenous sand-water mixture flows', Journal of Hydraulic Research, vol. 46 El 1, pp. 105-111, https://doi.org/10.1080/00221686.2008.9521945

Pullum, L, Graham, LWW \& Wu, J 2010, 'Bed establishment lengths under laminar flow', Proceedings of the 18th International Hydrotransport Conference, BHR Group, Cranfield, pp. 261-276.

Rhee, C van 2017, 'Simulation of the settling of solids in a non-Newtonian fluid', in J Sobota, P Vlasak \& V Matousek (eds) Proceedings of the 18th International Conference on Transport and Sedimentation of Solid Particles, pp. 265-270.

Sanders, RS, Schaan, J, Gillies, RG, Mckibben, MJ, Sun, R \& Shook, CA 2002, 'Solids transport in laminar, open-channel flow of non-Newtonian slurries', Proceedings of the 15th International Conference on Hydraulic Transport of Solids in Pipes: Hydrotransport 15, BHR Group, Cranfield, pp. 597-611.

Sisson, R, Lacoste-Bouchet, P, Vera, M, Costello, M, Hedblom, E, Sheets, B, Nesler, D, Solseng, P, Fandrey, A, van Kesteren, WGM, Talmon, AM \& Sittoni, L 2012, 'An analytical model for tailings deposition developed from pilot-scale testing', in D Sego, GW Wilson \& N Beier (eds), Proceedings of the 3rd International Oil Sands Tailings Conference, University of Alberta, Edmonton, pp. 53-63.

Sittoni, L, Talmon, AM, Hanssen, JLJ, van Es, HE, Kester JATM van, Uittenbogaard, RE, Winterwerp, JC \& van Rhee, C 2016, 'Optimizing tailings deposition to maximize fines capture: Latest advance in predictive modeling tools', in D Sego, GW Wilson \& NA Beier (eds), Proceedings of the 5th International Oil Sands Tailings Conference, University of Alberta, Edmonton, pp. 32-39.

Spelay, RB 2007, Solids transport in laminar, open channel flow of non-Newtonian slurries, PhD thesis, University of Saskatchewan, Saskatoon.

Talmon, AM \& Mastbergen, DR 2004, 'Solids transport by drilling fluids: Concentrated bentonite sand-slurries', in P Vlasák, P Filip \& J Sobota (eds), Proceedings of the 12th International Conference on Transport and Sedimentation of Solid Particles, Institute of Hydrodynamics, Academy of Sciences of the Czech Republic, Prague, pp. 641-649.

Talmon, AM, van Kesteren, WGM, Sittoni, L, \& Hedblom, E 2014a, 'Shear cell tests for quantification of tailings segregation', The Canadian Journal of Chemical Engineering, vol. 92, pp. 362-373.

Talmon, AM, van Kesteren, WGM, Mastbergen, DR, Pennekamp, JGS \& Sheets, B 2014b, 'Calculation methodology for segregation of solids in non-Newtonian carrier fluids', in RJ Jewell, AB Fourie, PS Wells \& D van Zyl (eds), Proceedings of the 17th International Seminar on Paste and Thickened Tailings, InfoMine Inc., Vancouver, pp. 139-153.

Thomas, AD 1979, 'Settling of particles in a horizontally sheared Bingham plastic', in PHT Uhlherr (ed.), Proceedings of the 1st National Conference on Rheology, Monash University, Melbourne, pp. 89-92.

Thomas, AD 1999, 'The influence of coarse particles on the rheology of fine particle slurries', Proceedings of Rheology in the Mineral Industry II, United Engineering Foundation, New York, pp. 113-123.

Thomas, AD 2010, 'Method of determining the inherent viscosity of a slurry and other rheological trends as illustrated by a data bank of over 200 different slurries', in N Heywood (ed.), Proceedings of the 18th International Conference on Hydrotransport, BHR Group, Cranfield, pp. 325-339.

Treinen, JM 2017, Modelling Transport and Deposition of Coarse Particles in Viscoplastic Tailings Beach Flows, PhD thesis, University of Colorado Boulder, Boulder.

Van Kesteren, WGM, van de Ree, T, Talmon, AM, de Lucas Pardo, M, Luger, D \& Sittoni, L 2015, 'Large-scale experimental study of high density slurries deposition on beaches', in J Sobota and C van Rhee (eds) Proceedings of the 17th International Conference on Transport and Sedimentation of Solid Particles, pp. 147-154.

Van Es, HE 2017, Development of A Numerical Model for Dynamic Depositioning of Non-Newtonian Slurries, MSc thesis, Delft University of Technology, Delft.

Wilson, KC \& Horsley, RR 2004, 'Calculating fall velocities in non-Newtonian (and Newtonian) fluids: a new view', in N Heywood (ed.), Proceedings of the 16th International Conference on Hydraulic Transport of Solids in Pipes: Hydrotransport 16, BHR Group, Cranfield, pp. 37-46. 
